ThE WORKS OF JOHN DRYDEN

Editor

VINTON A. DEARING 
Volume Sixteen EDITOR

Vinton A. Dearing 



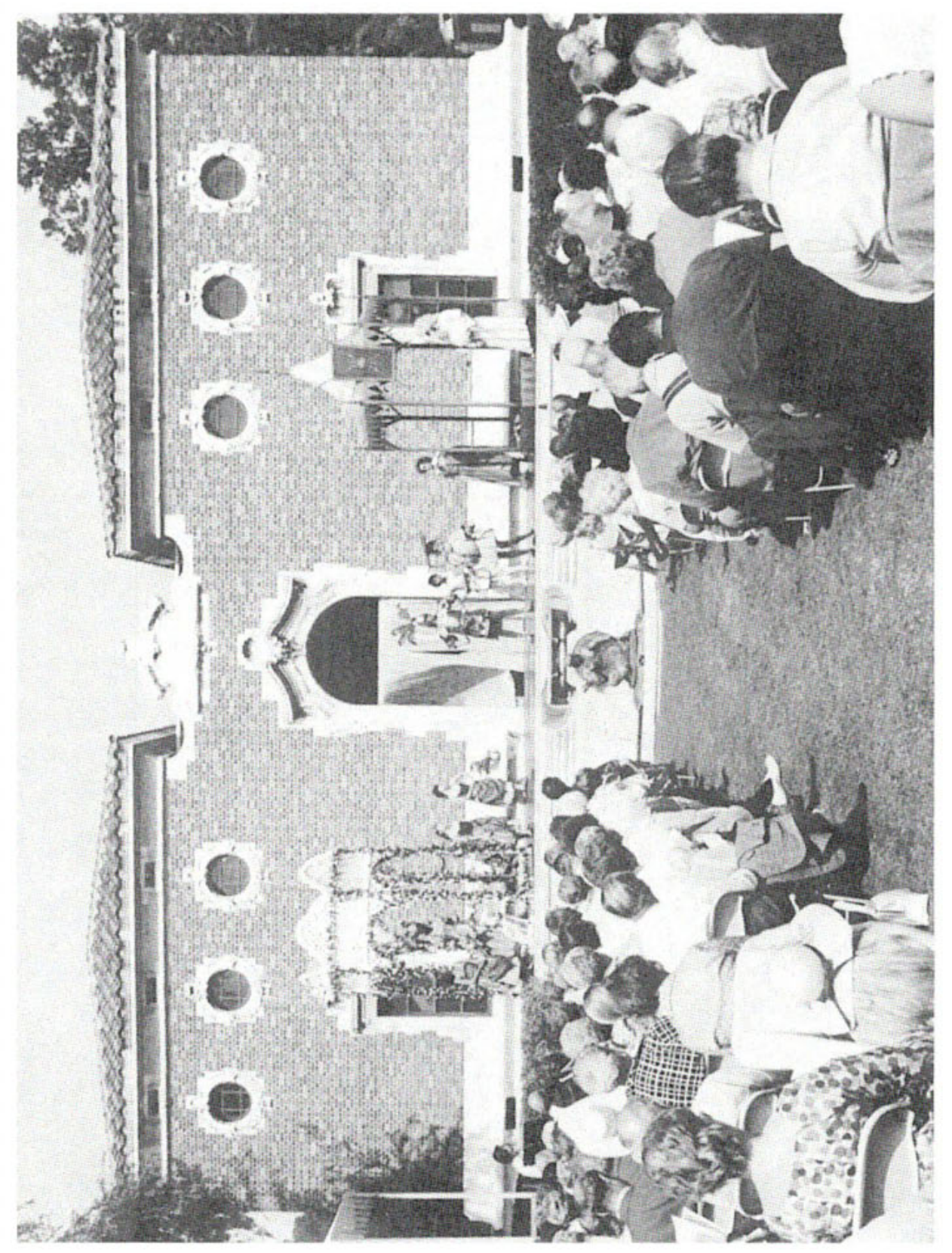

ل्र 


\title{
The Works
}

\section{of John Dryden}

\author{
Plays \\ KING ARTHUR \\ CLEOMENES \\ LOVE TRIUMPHANT \\ CONTRIBUTIONS TO THE PILGRIM
}

\section{University of California Press \\ Berkeley Los Angeles London \\ 1996}




\section{UNIVERSITY OF CALIFORNIA PRESS \\ Berkeley and Los Angeles, California \\ UNIVERSITY OF CALIFORNIA PRESS, LTD. \\ London, England}

The copy texts of this edition have been drawn in the main from the Dryden Collection of the William Andrews Clark Memorial Library

Copyright (c) 2996 by The Regents of the University of California

ISBN: 0-520-08766-6

Library of Congress Catalog Card Number: 55-7149

Designed by Ward Ritchie 
To

Mary Dearing Langworthy

Timothy Harvard Langworthy

John Vinton Langworthy 
The preparation of this volume of the California edition of The Works of John Dryden has been made possible in part by a grant from the National Endowment for the Humanities, an independent federal agency, and by a matching grant from The UCLA Foundation. 